\title{
X-linked acrogigantism syndrome: clinical profile and therapeutic responses
}

\author{
Albert Beckers 1,", Maya Beth Lodish ${ }^{2,{ }^{*},}$, Giampaolo Trivellin ${ }^{2}$, Liliya Rostomyan', \\ Misu Lee ${ }^{3}$, Fabio R Faucz ${ }^{2}$, Bo Yuan ${ }^{4}$, Catherine S Choong ${ }^{5}$, Jean-Hubert Caberg ${ }^{6}$, \\ Elisa Verrua ${ }^{7}$, Luciana Ansaneli Naves ${ }^{8}$, Tim D Cheetham ${ }^{9}$, Jacques Young ${ }^{10}$, \\ Philippe A Lysy ${ }^{11}$, Patrick Petrossians ${ }^{1}$, Andrew Cotterill ${ }^{12}$, Nalini Samir Shah ${ }^{13}$, \\ Daniel Metzger $^{14}$, Emilie Castermans ${ }^{6}$, Maria Rosaria Ambrosio ${ }^{15}$, Chiara Villa ${ }^{1,16,17}$, \\ Natalia Strebkova ${ }^{18}$, Nadia Mazerkina ${ }^{19}$, Stéphan Gaillard ${ }^{20}$, \\ Gustavo Barcelos Barra ${ }^{21}$, Luis Augusto Casulari ${ }^{8}$, Sebastian J Neggers ${ }^{22}$, \\ Roberto Salvatori ${ }^{23}$, Marie-Lise Jaffrain-Rea ${ }^{24}$, Margaret Zacharin ${ }^{25}$, \\ Beatriz Lecumberri Santamaria ${ }^{26}$, Sabina Zacharieva ${ }^{27}$, Ee Mun Lim ${ }^{28}$, \\ Giovanna Mantovani ${ }^{7}$, Maria Chaira Zatelli ${ }^{15}$, Michael T Collins ${ }^{29}$, Jean- \\ François Bonneville', Martha Quezado ${ }^{30}$, Prashant Chittiboina ${ }^{31}$, Edward H Oldfield ${ }^{32}$, \\ Vincent Bours ${ }^{6}$, Pengfei Liu ${ }^{4}$, Wouter W de Herder ${ }^{22}$, Natalia Pellegata ${ }^{3}$, \\ James R Lupski ${ }^{4,33,34}$, Adrian F Daly ${ }^{1,+}$ and Constantine A Stratakis ${ }^{2,+}$ \\ ${ }^{1}$ Department of Endocrinology, Centre Hospitalier Universitaire de Liège, University of Liège, \\ Domaine Universitaire du Sart-Tilman, 4000 Liège, Belgium \\ ${ }^{2}$ Program on Developmental Endocrinology and Genetics, Section on Endocrinology and Genetics, Eunice Kennedy \\ Shriver National Institute of Child Health and Human Development (NICHD), National Institutes of Health (NIH), \\ NIH-Clinical Research Center, 10 Center Drive, Building 10, Room 1-3330, MSC1103, Bethesda, \\ Maryland 20892-1862, USA \\ ${ }^{3}$ Helmholtz Zentrum München, Institute of Pathology, Neuherberg, Germany \\ ${ }^{4}$ Department of Molecular and Human Genetics, Baylor College of Medicine, Houston, Texas, USA \\ ${ }^{5}$ Department of Pediatric Endocrinology and Diabetes, Princess Margaret Hospital for Children, Subiaco, \\ Western Australia, Australia \\ ${ }^{6}$ Department of Clinical Genetics, Centre Hospitalier Universitaire de Liège, University of Liège, Liège, Belgium \\ ${ }^{7}$ Endocrinology and Diabetology Unit, Fondazione IRCCS Ca' Granda Ospedale Maggiore Policlinico, Department of \\ Clinical Sciences and Community Health, University of Milan, Milan, Italy \\ ${ }^{8}$ Department of Endocrinology, University of Brasilia, Brasilia, Brazil \\ ${ }^{9}$ Department of Paediatric Endocrinology, Royal Victoria Infirmary, Newcastle University, Newcastle upon Tyne, UK \\ ${ }^{10}$ INSERM U 693, GHU Paris-Sud - Hôpital de Bicêtre, 78 rue du Général Leclerc, 94270 Le Kremlin-Bicêtre, France \\ ${ }^{11}$ Pediatric Endocrinology Unit, Université Catholique de Louvain, Bruxelles, Belgium \\ ${ }^{12}$ Mater Medical Research Institute, University of Queensland, Brisbane, Queensland, Australia \\ ${ }^{13}$ Department of Endocrinology, KEM Hospital, Mumbai, India \\ ${ }^{14}$ Endocrinology and Diabetes Unit, BC Children's Hospital, Vancouver, British Columbia, Canada \\ ${ }^{15}$ Section of Endocrinology, Department of Medical Sciences, University of Ferrara, Ferrara, Italy \\ ${ }^{16}$ Service d'Anatomie et Cytologie Pathologiques, Hopital Foch, Suresnes, France \\ ${ }^{17}$ INSERM Unité 1016, Institut Cochin, Hopital Cochin, Université Paris Descartes, Paris, France \\ ${ }^{18}$ Institute of Pediatric Endocrinology, Endocrinological Research Centre, Moscow, Russia \\ ${ }^{19}$ Burdenko Neurosurgery Institute, Moscow, Russia \\ ${ }^{20}$ Department of Neurosurgery, Hopital Foch, Suresnes, France \\ ${ }^{21}$ Laboratorio Sabin, Brasilia, Brazil \\ ${ }^{22}$ Section of Endocrinology, Department of Medicine, Erasmus University Medical Center Rotterdam/ \\ Pituitary Center Rotterdam, Rotterdam, The Netherlands \\ ${ }^{23}$ Department of Endocrinology, Johns Hopkins University, Baltimore, Maryland, USA \\ ${ }^{24}$ Department of Endocrinology, University of L'Aquila, IRCCS, L'Aquila, and Neuromed, Pozilli, Italy \\ ${ }^{25}$ Department of Endocrinology and Diabetes, The Royal Children's Hospital, Melbourne, Victoria, Australia \\ ${ }^{26}$ Department of Endocrinology, Hospital Universitario La Paz, Madrid, Spain \\ ${ }^{27}$ Clinical Center of Endocrinology and Gerontology, Medical University of Sofia, Sofia, Bulgaria
}

http://erc.endocrinology-journals.org DOI: 10.1530/ERC-15-0038
(C) 2015 Society for Endocrinology Printed in Great Britain
Published by Bioscientifica Ltd. 


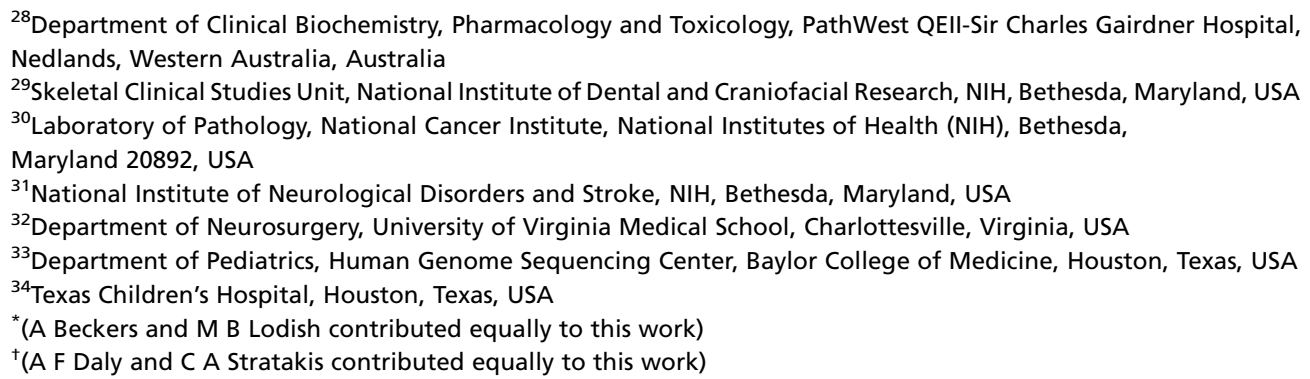

Correspondence should be addressed to A Beckers; C A Stratakis Emails

albert.beckers@chu.ulg.ac.be; stratakc@mail.nih.gov

\begin{abstract}
X-linked acrogigantism (X-LAG) is a new syndrome of pituitary gigantism, caused by microduplications on chromosome Xq26.3, encompassing the gene GPR101, which is highly upregulated in pituitary tumors. We conducted this study to explore the clinical, radiological, and hormonal phenotype and responses to therapy in patients with X-LAG syndrome. The study included 18 patients (13 sporadic) with X-LAG and microduplication of chromosome Xq26.3. All sporadic cases had unique duplications and the inheritance pattern in two families was dominant, with all Xq26.3 duplication carriers being affected. Patients began to grow rapidly as early as 2-3 months of age (median 12 months). At diagnosis (median delay 27 months), patients had a median height and weight standard deviation scores (SDS) of $>+3.9$ SDS. Apart from the increased overall body size, the children had acromegalic symptoms including acral enlargement and facial coarsening. More than a third of cases had increased appetite. Patients had marked hypersecretion of GH/IGF1 and usually prolactin, due to a pituitary macroadenoma or hyperplasia. Primary neurosurgical control was achieved with extensive anterior pituitary resection, but postoperative hypopituitarism was frequent. Control with somatostatin analogs was not readily achieved despite moderate to high levels of expression of somatostatin receptor subtype-2 in tumor tissue. Postoperative use of adjuvant pegvisomant resulted in control of IGF1 in all five cases where it was employed. X-LAG is a new infant-onset gigantism syndrome that has a severe clinical phenotype leading to challenging disease management.
\end{abstract}
Key Words
- gigantism
- X chromosome
- pituitary adenoma
- pediatric
- X-LAG syndrome
- GPR101
- FIPA
- duplication

\title{
Introduction
}

Pituitary gigantism is a rare condition associated with hypersecretion of growth hormone $(\mathrm{GH})$ by a pituitary tumor or hyperplasia before the complete fusion of growth plates, leading to pathological tall stature (Eugster \& Pescovitz 1999, Davies \& Cheetham 2014). Chronic GH hypersecretion leads to the development of signs and symptoms of acromegaly, which continue to develop after the attainment of final height. Although it is a wellrecognized condition among the medical and general populations (de Herder 2015), the genetic etiology of pituitary gigantism remained poorly understood until recently. Pituitary gigantism can occur as a feature of a number of monogenic disorders. Approximately one-third of acromegaly patients with germline mutations in the aryl hydrocarbon receptor interacting protein $(A I P)$ gene have gigantism (Beckers et al. 2013), and additional etiologies include mosaicism for GNAS mutations in McCuneAlbright syndrome (MAS), germline PRKAR1A mutations in Carney complex, or rarely MEN1 mutations (Stratakis et al. 2000, Salenave et al. 2014, Salpea \& Stratakis 2014).

We have recently described a new disorder of X-linked acrogigantism (X-LAG) that is due to microduplications of chromosome Xq26.3 (MIM\#300942) that involve the gene for the orphan $G$ protein-coupled receptor (GPCR), GPR101, which is highly upregulated in pituitary tumors from affected patients (Trivellin et al. 2014). X-LAG is a distinctive clinical entity that is characterized by excessive growth, usually beginning during the first year

Published by Bioscientifica Ltd 
of life in previously normal infants. The overgrowth is caused by GH hypersecretion from hyperplasia and/or a pituitary macroadenoma. X-LAG can occur as a sporadic condition or can present as familial isolated pituitary adenomas (FIPAs) in acrogigantism kindreds. This newly described condition is rare and the phenotype is incompletely characterized, particularly in terms of clinical responses to treatment. The aim of the current study was to clinically characterize X-LAG in an expanded cohort of 18 affected patients.

\section{Methods}

The study population consisted of 18 patients with X-LAG syndrome, of whom five were familial and 13 were sporadic (basic diagnostic/genetic data were presented on 13 cases in Trivellin et al. (2014)). Patients underwent genetic diagnosis (peripheral blood DNA) using clinical array comparative genomic hybridization (aCGH) and research-based high-definition array CGH. All tested patients had a microduplication of chromosome Xq26.3. Breakpoint analyses were performed using long-range PCR techniques. Fluorescence in situ hybridization (FISH) studies using Xq26.3 microduplication specific probes were also performed on peripheral blood leukocytes from a subset of patients as described previously (Trivellin et al. 2014). During this study a comprehensive set of data on the demographic, clinical, radiological, hormonal, pathological, and therapeutic outcomes in the patient population was collected under the following headings (individual criteria are listed in Supplementary materials and methods, see section on supplementary data given at the end of this article): demographics and background parameters; birth and family characteristics; growth disorder characteristics; symptoms and hormone disturbances; pituitary imaging characteristics; treatment; outcomes.

\section{Pathology}

Staining of formalin-fixed paraffin-embedded (FFPE) tissue samples of pituitary tumors for pituitary hormones (GH, PRL, ACTH, FSH, LH, and TSH), and GH-releasing hormone receptor (GHRHR) were performed as described previously (Magri et al. 2010, Trivellin et al. 2014). Immunohistochemical stains for somatostatin receptors (SSTRs) were performed using an automated immunostainer (Ventana Medical Systems, Tucson, AZ, USA) as reported previously (Lee et al. 2013). The SuperSentitive immunohistochemistry (IHC) detection system from BioGenex (Fremon, CA, USA) was used to visualize the antibody binding following the manufacturer's instructions. Sections were counterstained with Mayer's Haemalum, dehydrated, and coverslips were fitted. The primary antibodies directed against SSTR2 (clone UMB-1 reacting with the SSTR2a isoform, dilution: 1:500), SSTR3 (clone UMB-5, dilution: 1:750), and SSTR5 (clone UMB-4, dilution: 1:75) were purchased from Abcam (Cambridge, MA, USA). Sections of normal pancreas were used as a positive control and included in each run. Sections incubated without the primary antibody were included in each batch as a negative control. Immunostains were evaluated semiquantitatively by two individuals on acquired images. An immunoreactive score (IRS) was recorded for each section as reported (Lee et al. 2014). Briefly, the IRS was generated on the basis of the intensity of the staining (no staining, 0; mild, 1; moderate, 2; strong, 3) and the percentage of cells showing membranous or cytoplasmic expression (no positive cells, $0 ;<10 \%$ positive cells, 1 ; $10-50 \%$ positive cells, 2 ; $51-80 \%$ positive cells, 3 ; and $>80 \%$ positive cells, 4 ). The overall IRS was calculated as (percentage of positive cells) $\times$ (intensity of staining). We considered the staining as being negative for IRS 0 and 1 , weakly positive for IRS 2 and 3, moderately positive for IRS $4-8$, and strongly positive for IRS $>8$. Immunostains for anterior pituitary hormones, Ki67 (MIB1), and AIP were performed as described (Jaffrain-Rea et al. 2009, Villa et al. 2011). Briefly, AIP/ARA9 antibody (Novus Biologicals, Littleton, Colorado, USA) was used at a dilution of 1:2000 and processed using an automated protocol for Benchmark Ventana.

\section{Statistical analysis}

Data were collated and expressed as medians and ranges. As the data were not normally distributed, comparisons of data between subgroups by sex were performed using the Mann-Whitney $U$ test.

\section{Literature review}

We conducted a comprehensive study of the literature on gigantism from the extensive historical collection of one of the authors ( $\mathrm{W} \mathrm{W} \mathrm{dH}$ ) that includes images, medical information, family accounts, media reports, and other items. These items formed the basis of a secondary search of the medical literature in terms of original scientific publications, books, and manuscripts dealing with gigantism and acromegaly among children. Cases in which strong pictorial, medical, and narrative evidence of onset of overgrowth during childhood (before the age of 8) or where gigantism had already been well established by

Published by Bioscientifica Ltd. 
height measurements before the age of 10 years were identified and data were extracted.

The study on gigantism and the genetic studies of patients with pituitary tumors were approved by the Ethics Committee of the Centre Hospitalier Universitaire de Liège, Belgium. The studies at the National Institutes of Health (NIH) Clinical Research Center were approved by the National Institute of Child Health and Human Development Institutional review board (NICHD IRB). Patients or parents/guardians provided informed consent; children over the age of 8 years that were seen at the NIH provided assent. The study was conducted according to the Declaration of Helsinki on the Ethical Principles for Medical Research Involving Human Subjects.

\section{Results}

\section{Demographics and genetic diagnosis}

Most patients with X-LAG syndrome were sporadic (13/18; 72.2\%). Two families that presented with FIPA had three and two affected members respectively. The ethnic backgrounds were diverse: Caucasian European, South East Asian, Indian subcontinent, First Nations Canadian, and Latino-Afro-Caribbean backgrounds were all seen. All patients were the offspring of non-consanguineous parents. Apart from the familial cases, there were no histories of growth disorders in any relatives of the affected patients. Duplications of an approximately $500 \mathrm{~kb}$ region on chromosome Xq26.3 (involving CD4OLG, ARHGEF6, RBMX, and GPR101) were observed for both newly and previously reported cases (Fig. 1; Trivellin et al. 2014). Studied cases also shared the previously noted smallest regions of overlap on a HD-aCGH. Breakpoint analyses revealed that all non-familial cases were unique rearrangements, which are likely to be mediated by a fork stalling and template switching/microhomology-mediated break-induced replication (FoSTeS/MMBIR) mechanism (Lee et al. 2007, Hastings et al. 2009, Zhang et al. 2009). Duplications were visualized by FISH in all cases studied (Fig. 1).

\section{Growth and disease characteristics}

Patients were generally born at full-term (one sporadic case was born at 35 weeks) from uncomplicated pregnancies (Fig. 1 and Table 1). In all but two of the cases, the birth weight, length, and head circumference were normal. One female patient, the mother of two familial cases, had a birth length in excess of the 97th centile, although the birth weight was normal, while another sporadic case was small for gestational age. Overall, in the X-LAG cohort, the median age at the onset of rapid growth was 12 months (range: 2-48 months) and, although females had a younger age at the onset of rapid growth than males, this was not statistically significant (10.5 versus 14.0 months respectively; $P=\mathrm{NS}$ ). The median age at diagnosis was 41 months (range: 14-264 months), and again females were younger than males at diagnosis (40 versus 56 months respectively; $P=\mathrm{NS}$ ). At diagnosis, the median height standard deviation score (SDS) was +3.9 (range: +1.9 to +7.6 ). The median weight SDS was similarly increased at diagnosis: $(+4.4$; range: +3.0 to +9.3$)$.

The presenting symptoms at diagnosis are shown in Table 2. Apart from abnormally increased growth in all patients, the most frequent complaints at presentation were typically acromegalic-type signs, such as, acral enlargement (38.9\%) and coarsened facial features (33.3\%). Some of the physical features and characteristics are illustrated in Fig. 2. Interestingly, 7/18 (38.9\%) patients had a preceding history of increased appetite or other food-seeking behavior, a feature that is not typical of other forms of gigantism. Four patients (22.2\%) had acanthosis nigricans at diagnosis. At diagnosis, fasting insulin levels were available for 12 patients, of whom six demonstrated fasting hyperinsulinemia (including all with acanthosis nigricans). No patient had diabetes mellitus at diagnosis or during follow-up. Neurological symptoms such as headache, visual field defects, ataxia, and seizure occurred in one patient each.

\section{Radiological characteristics}

MRI findings at diagnosis in a selection of the patient population are shown in Fig. 3. There was some variability in the tumor sizes and appearances, from large homogeneous bean- or peanut-shaped tumors, to those with diffuse pituitary enlargement suggestive of hyperplasia. All patients had pituitary abnormalities at diagnosis, of which most appeared to be a macroadenoma on MRI (14/18), while the remaining patients had pituitary enlargement without an identifiable adenoma. The median tumor diameter was $18 \mathrm{~mm}$ (range: 10-39 mm). Tumor extension to the optic chiasm was frequent, occurring in 12 patients, whereas invasion of the cavernous sinus was present in only two patients at diagnosis. There were no statistically significant differences in radiological characteristics between males and females.

\section{Hormonal measures}

GH levels were universally elevated in all patients at diagnosis. Notably, the random GH levels at diagnosis were usually markedly increased, with a median level that

Published by Bioscientifica Ltd 
A

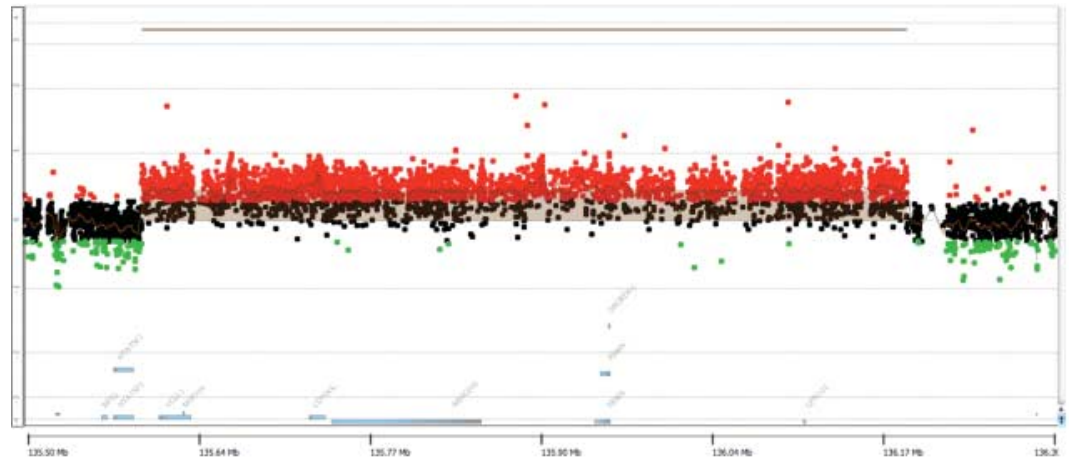

ChrX: 136192229 (unique sequence)

PROX TTCTITGAGTHARARTITGATCACATMTGATGARGGAAATGGGGCCCCATCCTTATCCAARGGGTCCTAAGTGTCCACTGGTACAAGGTGCTGGGATAGA BR TTCTTTGAGTAAAAATTTGATCACATÄTGATGAAGGAAATGGGGGCCGCAAGGGGTTGCTGCAGTAGTCCAGTTGAGAGGTGATGGTTARTAGATGGTTA

ChrX: 135601430 (L2)
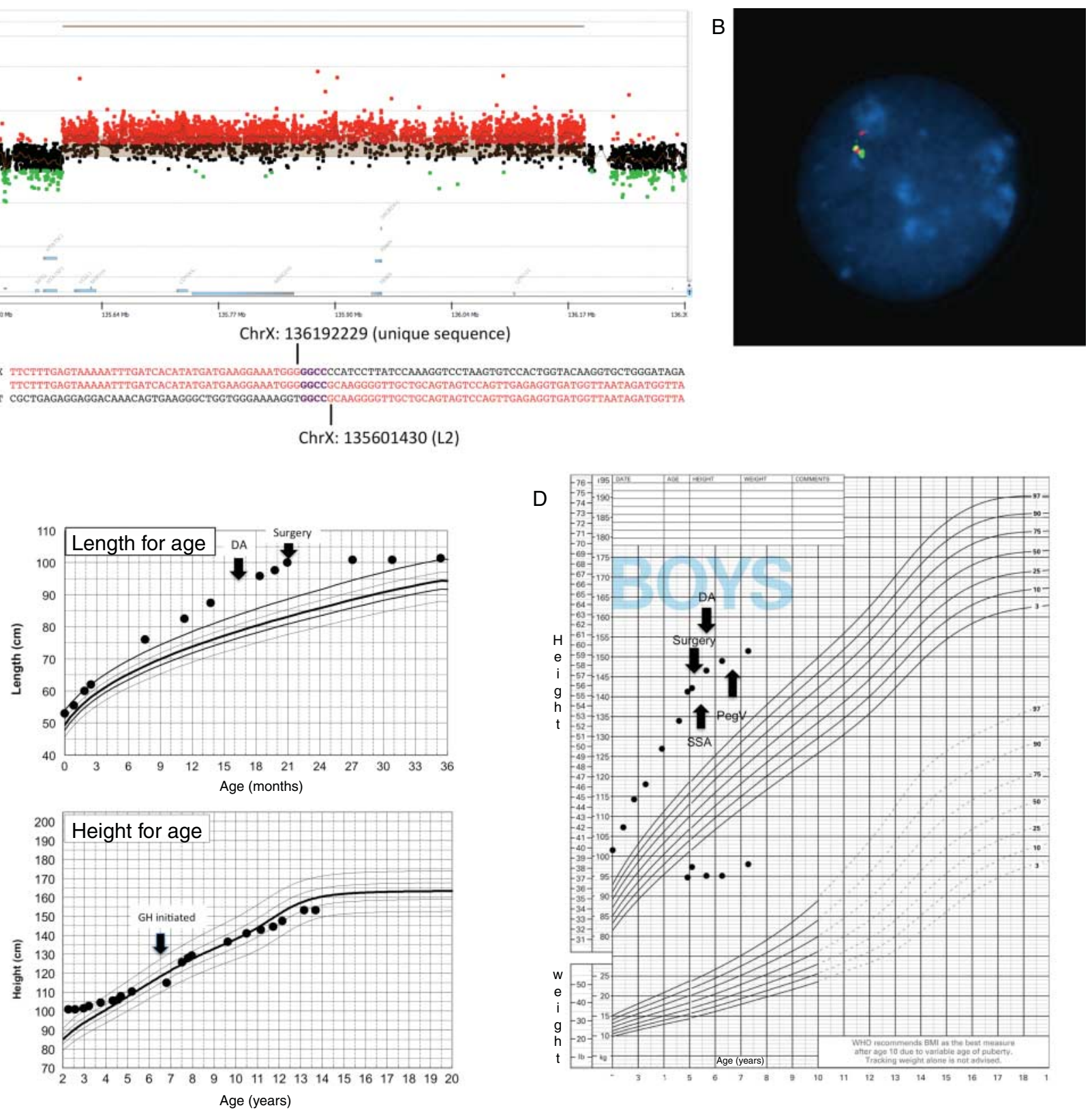

cabergoline (DA) and then surgery, after which time the total resection of the tumor was associated with flattening of her growth curve. She was diagnosed with panhypopituitarism and diabetes insipidus and required $\mathrm{GH}$ supplementation as indicated. Panel D shows the early growth of patient S1, a sporadic male case, which began between the ages of 9 and 12 months and continued despite subtotal surgical resection, SSA and DA; the introduction of pegvisomant (PegV) at the age of 6 led to normalization of IGF-1 and a decrease in gain in height. (female) and S1 (male). Panel C shows the growth of patient S5 that exceeded the 97 centile for length as early as 6 months of age; she was treated with

was 52.5 times the upper limit of the normal range (ULN) (range: six- to 300-fold ULN). Oral glucose tolerance test (OGTT) data were available for 14 cases; none showed GH suppression and four showed a paradoxical rise in $\mathrm{GH}$

during the test. IGF1 levels were also elevated at diagnosis in the 13 cases for which data was available; the medianfold increase above the ULN was 3.4 (range: 3.1- to 5.2-fold ULN). Prolactin levels at diagnosis were available for

Published by Bioscientifica Ltd 


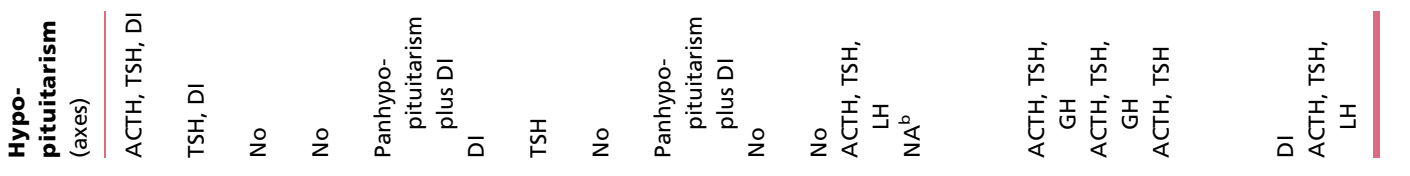

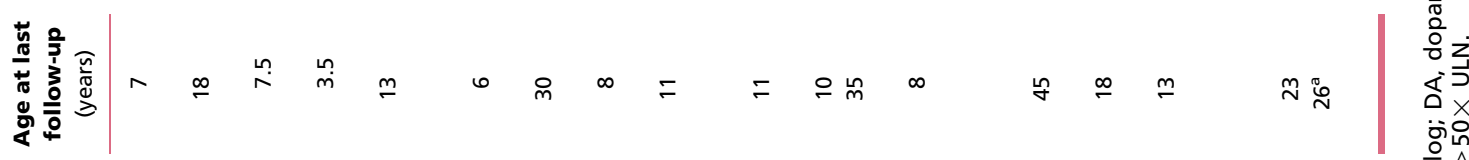

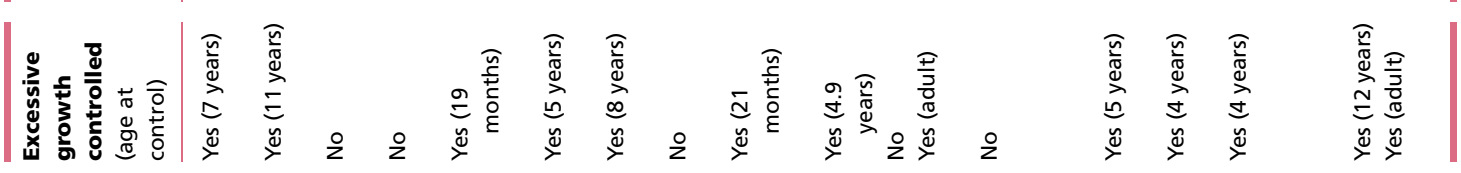

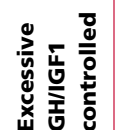

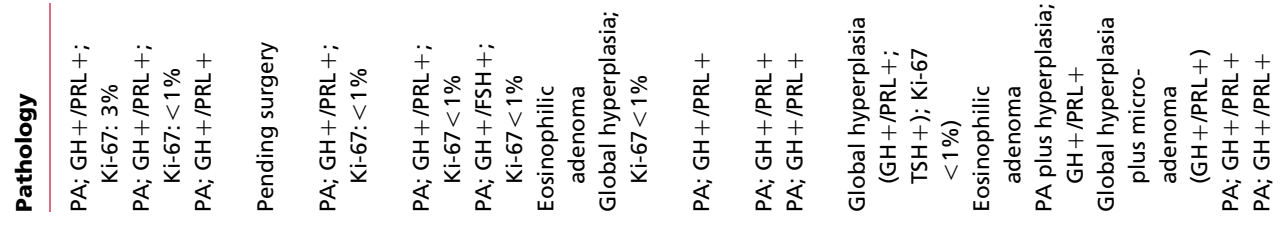

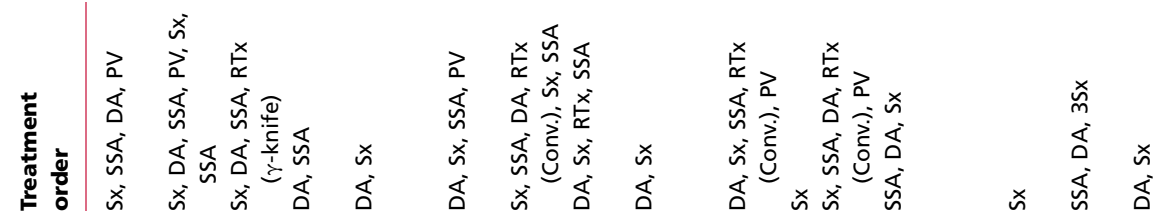

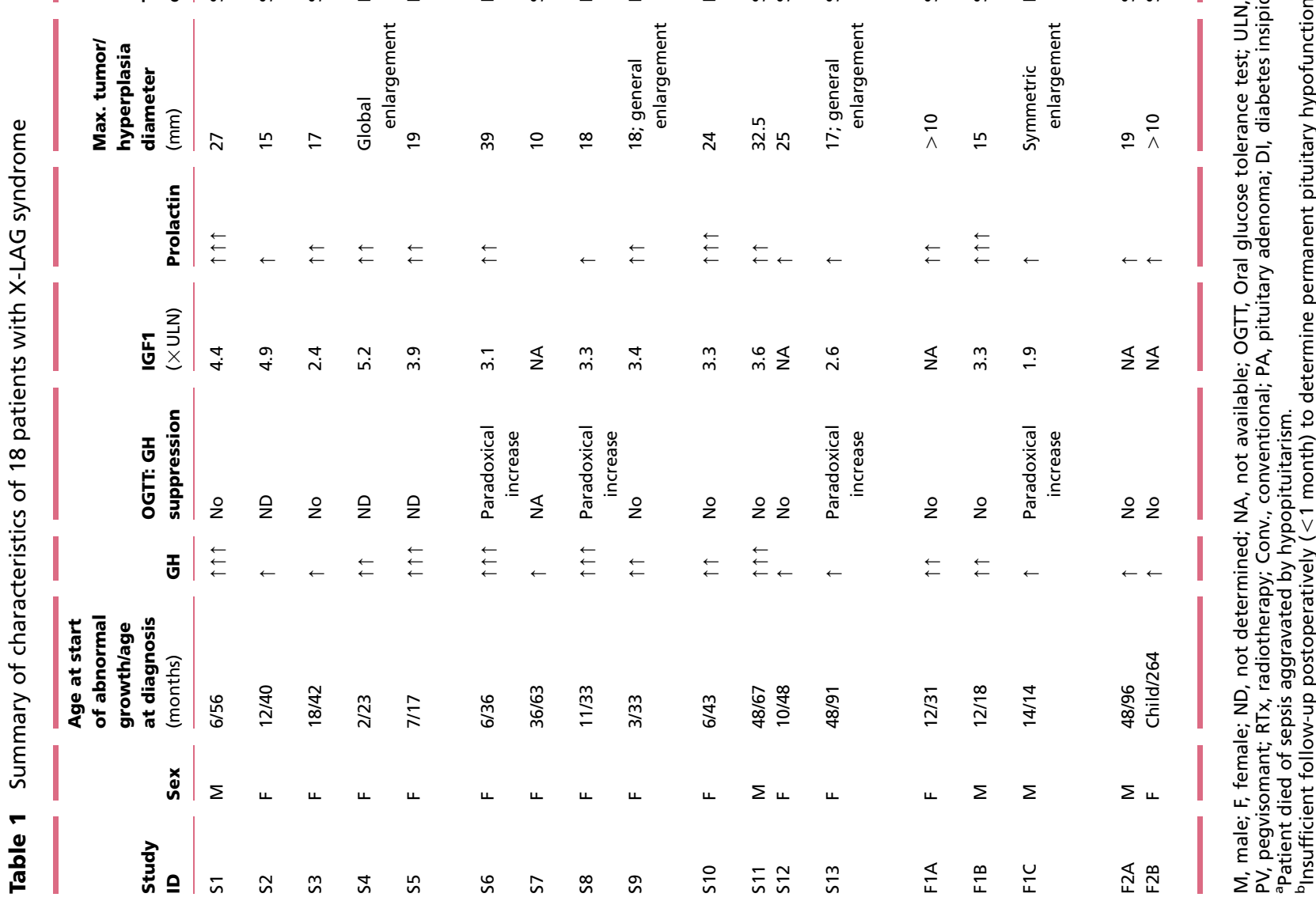


Table 2 Signs and symptoms reported in 18 patients with $\mathrm{X}$-LAG syndrome at presentation

\section{Sign/symptom}

Abnormally increased growth

Acral enlargement

Increased appetite

Coarsened facial features

Acanthosis nigricans

Sleep apnea/snoring

Excessive perspiration/body odor

Widening of interdental spaces

Abdominal distension/weight gain

Other (pubic hair, prognathism,

ataxia, visual field defect, seizure,

thickened skin, headache)

17 patients and were also elevated (median 18-fold over the ULN (range: 2.0- to 90.8-fold)). No patient exhibited galactorrhea. Five patients had GHRH levels measured at diagnosis and, in all cases, these were in the middle of or just above the ULN. At diagnosis, none of the patients exhibited hypopituitarism.

\section{Therapeutic responses and outcomes}

Management of the X-LAG patients was multimodal in the majority of cases and, in many cases, this was complex
(Table 1), as illustrated for two cases in Fig. 4. All but one of the 18 patients underwent neurosurgery, and for the remaining case, surgery is pending.

Nine patients underwent medical therapy as the initial modality (dopamine agonist (DA), mostly cabergoline (Dostinex): $n=7$; somatostatin analog (SSA): $n=2$ ) and none achieved control of either GH or PRL secretion despite the use of doses normally used in adult patients (SSA (duration 6-12 months): octreotide, $40 \mathrm{mg} / \mathrm{month}$; lanreotide, autogel $90 \mathrm{mg} / \mathrm{month}$. DA (duration 3-6 months): $0.25 \mathrm{mg} 3-5$ times weekly). In these patients, surgery was then employed (1-3 interventions) in all cases (apart from one patient awaiting surgery) and growth control was achieved in three cases but at the cost of hypopituitarism. Further use of SSA (dose: octreotide $30 \mathrm{mg} / \mathrm{month}$; lanreotide $90 \mathrm{mg} / \mathrm{month}$; duration: 6 month-5 years) did not lead to control in the remaining cases. Radiotherapy (conventional; follow-up: 5-20 years) also did not itself lead to permanent control of $\mathrm{GH}$ hypersecretion. Addition of pegvisomant (10 mg/day-20 mg four times per week) permitted control of IGF1 and excessive growth in three patients who had previously undergone surgery and who also had developed multiple pituitary axis deficiencies. Among the nine patients who underwent primary surgical resection, three had immediate GH/PRL control and
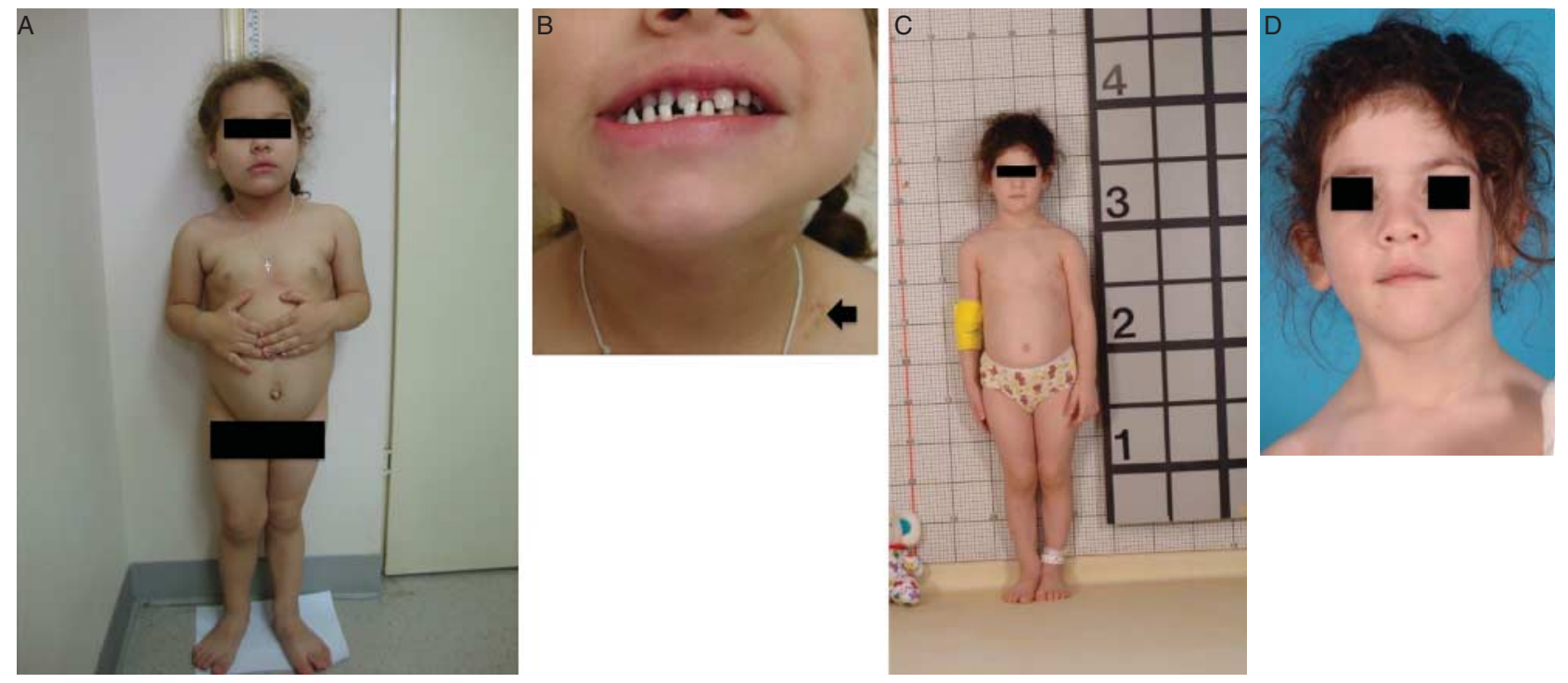

\section{Figure 2}

Physical changes in representative cases of X-LAG syndrome with Xq26.3 microduplications. (A) Patient S8 is shown at the age of 32 months at which time her height was $>4$ SDS (she had been growing at an abnormal rate since the age of 11 months). Of note are her large hands and feet and facial features that are moderately coarsened but well proportioned. Panel B shows widely spaced teeth and a patch of acanthosis nigricans on the left side of her neck. In panel C, patient $\$ 9$ who began to grow abnormally at the age of 3 months is pictured shortly after diagnosis (aged 33 months), when her height was $>5$ SDS and hands and feet are enlarged. Panel D shows her facial features, which include a large nose and prominent mandible and hypertelorism.
(C) 2015 Society for Endocrinology Printed in Great Britain 


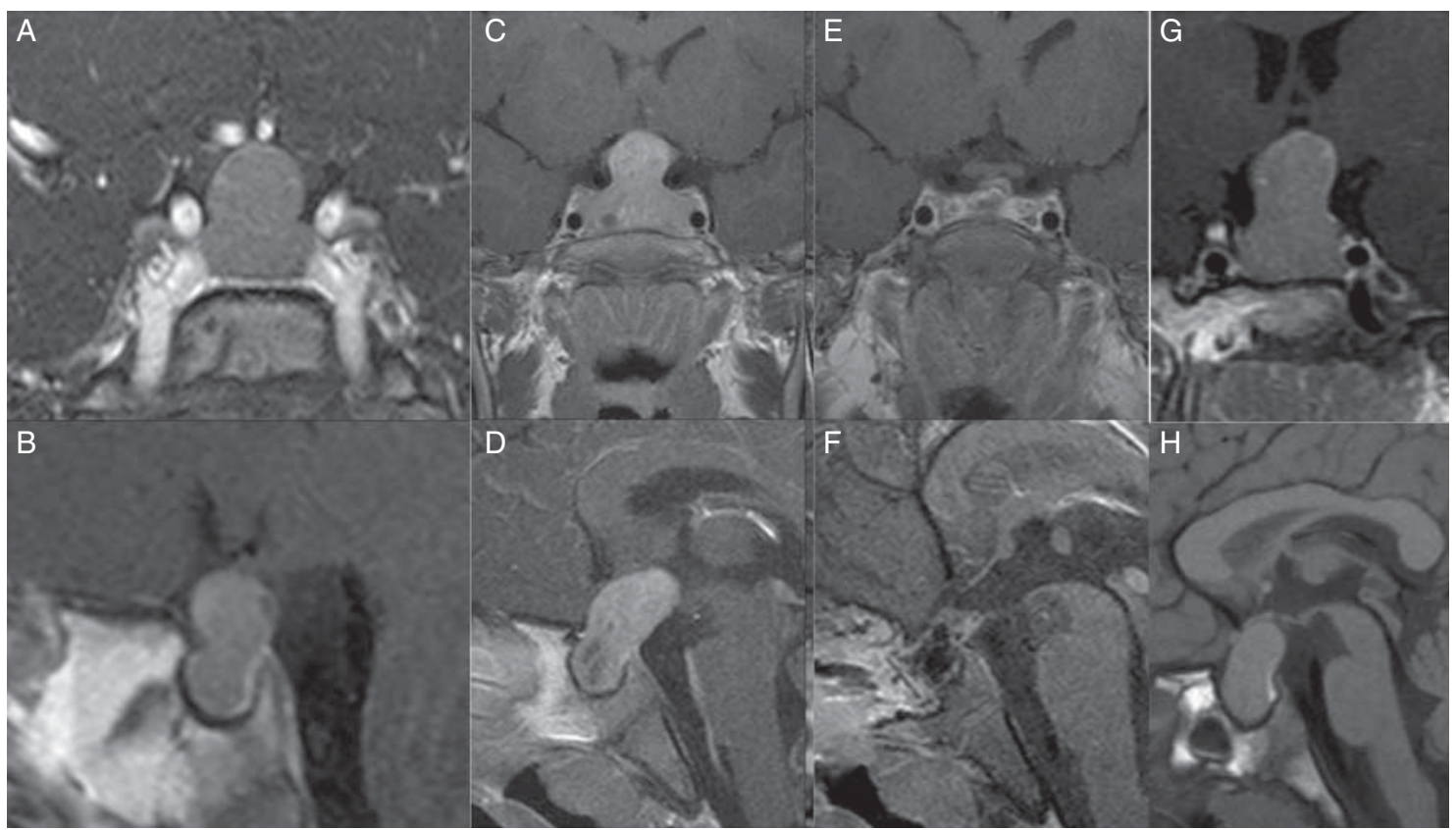

\section{Figure 3}

T1-weighted gadolinium-enhanced MRI images of female patient S9 at diagnosis (age 2 years 11 months), revealing a large, hypoattenuated hourglass ('peanut')-shaped mass within the sella with expansion of the diaphragma sella ( $A$ and $B$ ). Panels $C$ and $D$ show coronal and sagittal T1-weighted post-contrast images at diagnosis of female patient $\mathrm{S} 6$ (age 3 years) showing a large pituitary mass with marked upward and posterior extension and areas of degenerative changes. Postoperative

excessive growth was halted. The surgical control was followed in two cases by the development of panhypopituitarism and in one by diabetes insipidus (DI). For those patients in whom growth and GH secretion were not controlled by their initial surgery, the subsequent management was complex. Use of SSA (octreotide 30$40 \mathrm{mg} / \mathrm{month}$ depot, lanreotide $90 \mathrm{mg} / \mathrm{month}$ ) and DA ( $0.25 \mathrm{mg}$ two to seven times per week) postoperatively did not lead to hormonal or growth control, which was only achieved with combinations of radiotherapy (conventional or gamma-knife (follow-up $<1-10$ years)), repeated surgery, SSA, and finally pegvisomant (10-20 mg/day). SSA use was associated with a median reduction in GH and IGF1 of $37.5 \%$ and $15.2 \%$ respectively, whether used as primary or secondary therapy but in no case was the reduction sufficient to bring patients under hormonal control. None of the patients receiving pegvisomant experienced tumor expansion on therapy, even after more than 5 years of follow-up. Pasireotide was not available or was not used in the treatment of any of these patients.

Control of excessive growth was frequently accompanied by hypopituitarism (Table 1); one patient had images ( $E$ and $F$ ) from the same patient reveal that the adenoma has been visibly resected (hormonal and growth control, however, required SSA and pegvisomant). Panels $\mathrm{G}$ and $\mathrm{H}$ show coronal and sagittal T1-weighted MRI images of female patient $\mathrm{S} 10$ at diagnosis (aged 3 years), showing a large homogeneous pituitary mass extending superiorly and posteriorly ('bean shaped'); the posterior pituitary is clearly observed as a hyperattenuated posterior bright spot in panel $\mathrm{H}$.

$<1$ month of follow-up postoperatively and definitive growth control/hypopituitarism was difficult to determine. Four patients remain uncontrolled in terms of growth. One operated patient is awaiting availability of SSA and one patient is awaiting surgery but is receiving $100 \mu$ g s.c. octreotide daily plus DA; two other children are receiving $30-40 \mathrm{mg} / \mathrm{month}$ octreotide depot and DA, and have undergone radiotherapy (pegvisomant is not available in their jurisdiction).

\section{Pathological characteristics}

Overall, PAs alone were observed in 12 out of 17 patients that had undergone surgery, PA plus generalized hyperplasia in two out of 16 cases, and global hyperplasia alone in two out of 16 cases. As shown in Table 1, resected tissues were usually positive on IHC for both GH and PRL alone and most represented mixed GH-PRL-secreting PAs (Fig. 5). Proliferation rates (Ki-67) were low $(<1 \%)$ in tumors from six cases and were $2-3 \%$ in one adenoma.

For six patients, sufficient pituitary tumor tissue was available to undertake SSTR IHC. All six cases had moderate

Published by Bioscientifica Ltd. 


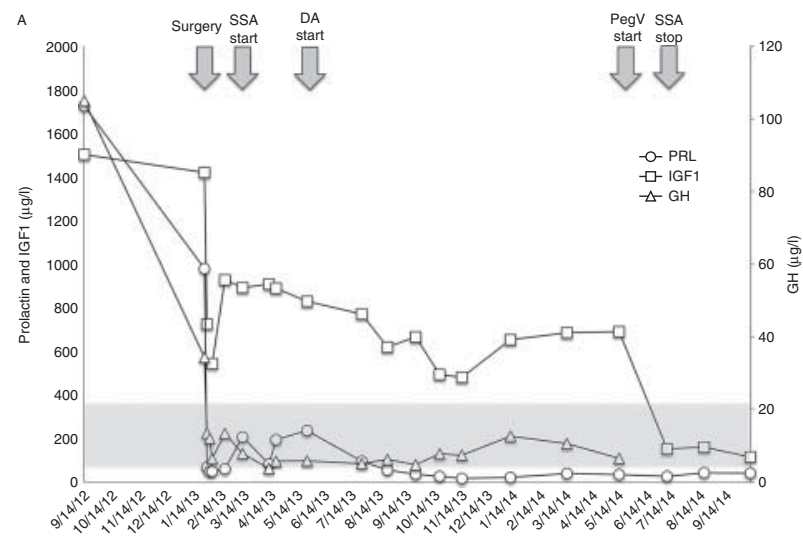

Figure 4

Time course of the effects of treatment modalities on GH, IGF1, and PRL in two representative patients with X-LAG syndrome. Panel A shows the evolution of sporadic patient $\mathrm{S1}$, a male who was diagnosed at the age of 56 months and underwent primary neurosurgical treatment to grossly resect the visible tumor. This surgical intervention lead to marked decreases in GH and PRL, but IGF1 remained very high (normal IGF1 range shown as a grey shaded area). Addition of an SSA (octreotide LAR $30 \mathrm{mg} / \mathrm{month}$ ) and later a DA (cabergoline $0.25 \mathrm{mg} 5 \times$ week) reduced the IGF1 by approximately $50 \%$ from the postoperative level but, as the IGF1 remained elevated and overgrowth continued, pegvisomant $(10 \mathrm{mg} /$ day $)$ was eventually added and led to a rapid decrease in IGF1, which allowed the SSA to be withdrawn. In panel B, a female sporadic case 56 first received a dopamine agonist and later underwent a neurosurgical intervention,

to high expression of SSTR2, the main target of somatostatin analogues such as octreotide and lanreotide, which was variable but moderate to high in all cases (IRSs 4-10). Despite the presence of SSTR2 in these cases, none of the six experienced hormonal or growth control in response to an SSA, even at doses generally used in adults. Five of the six tumors stained positively for SSTR5, although at a lower level than for SSTR2. Four tumors were stained for SSTR1 and SSTR3, while for two cases only the level of SSTR2 and SSTR5 could be assessed (Fig. 6). One of the four tumors was negative for SSTR1. SSTR3 is also highly expressed (average IRS 8.8) in the analyzed tumors. AIP expression was preserved at a moderate to high levels among these patients (Fig. 5).

\section{Discussion}

$\mathrm{X}$-LAG syndrome is a recently described cause of pituitary gigantism that is due to microduplication of chromosome Xq26.3 encompassing GPR101; the latter gene is highly upregulated in pituitary tumors from patients (Trivellin et al. 2014). In this study, we expand the number of described patients to 18 and focus for the first time, on aspects of the clinical management of these patients. A number of factors related to X-LAG syndrome combine to make the clinical

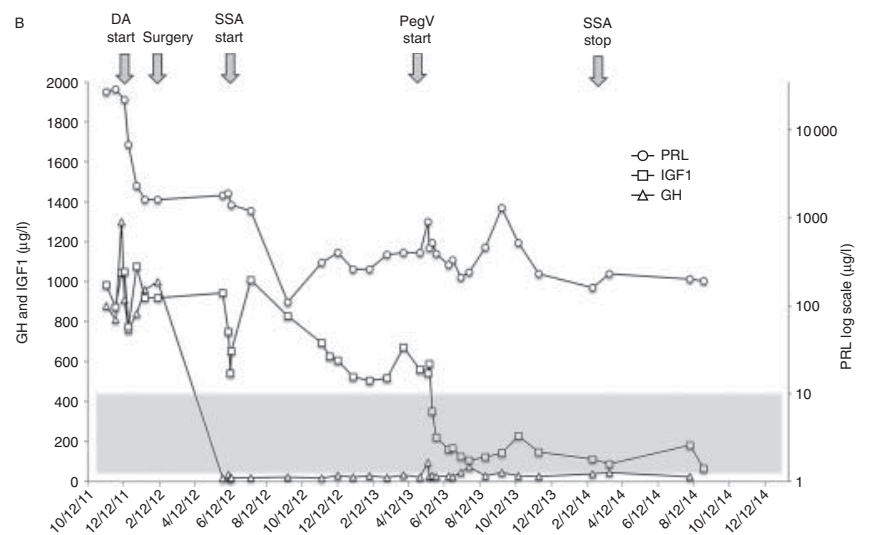

which removed the majority of the visible tumor. The postoperative $\mathrm{GH}$ levels were decreased greatly but remained elevated to an extent that IGF1 secretion was still greatly increased (normal range for IGF1 shown as a greyshaded area) and growth continued. Addition of a depot somatostatin analog (octreotide LAR $30 \mathrm{mg} / \mathrm{month}$ ) did not control IGF1 alone or in combination with cabergoline, although IGF1 levels showed approximately a $40 \%$ decrease from levels before SSAs were started. Owing to the lack of control and continuing somatic overgrowth, pegvisomant was added and it rapidly brought IGF1 levels and growth under control. As IGF1 levels dropped to approximately the lower limit of the normal range appropriate for the age of the patient ( 5 years), the SSA was withdrawn and the subsequent IGF1 level was in the middle of the normal range on pegvisomant $(10 \mathrm{mg} /$ day $)$.

management of this condition challenging. The age of onset of increased growth in X-LAG syndrome is significantly younger than that for other pituitary gigantism cases (Trivellin et al. 2014). In the current study, we confirm that patients with the Xq26.3 microduplication can exhibit overgrowth as young as 2-3 months of age, despite being normally sized newborns. Across the cohort, the onset of rapid abnormal growth always occurred before the age of 5 years, and in most patients it occurred before the end of the first year of life. As this is a newly described disease and, as infant overgrowth is rare and arguably less prioritized than failure to thrive, there was a delay in diagnosis in many cases. Overall, the median delay in diagnosis was 27 months. As a function of this delay (most likely), unchecked growth of the pituitary hyperplasia-adenoma led to most patients presenting with macroadenomas that had expanded to the level of the optic chiasm. Accompanying the pituitary abnormalities in X-LAG syndrome is very marked hypersecretion of GH/IGF1. In one case the PRL was not elevated and no PRL staining was seen in the tumor, indicating that PRL hypersecretion does not always occur in X-LAG syndrome. The action of chronic and markedly elevated GH and IGF1 on the young patients led to a phenotype of increased length/height (+3.9 SDS) and

Published by Bioscientifica Ltd. 

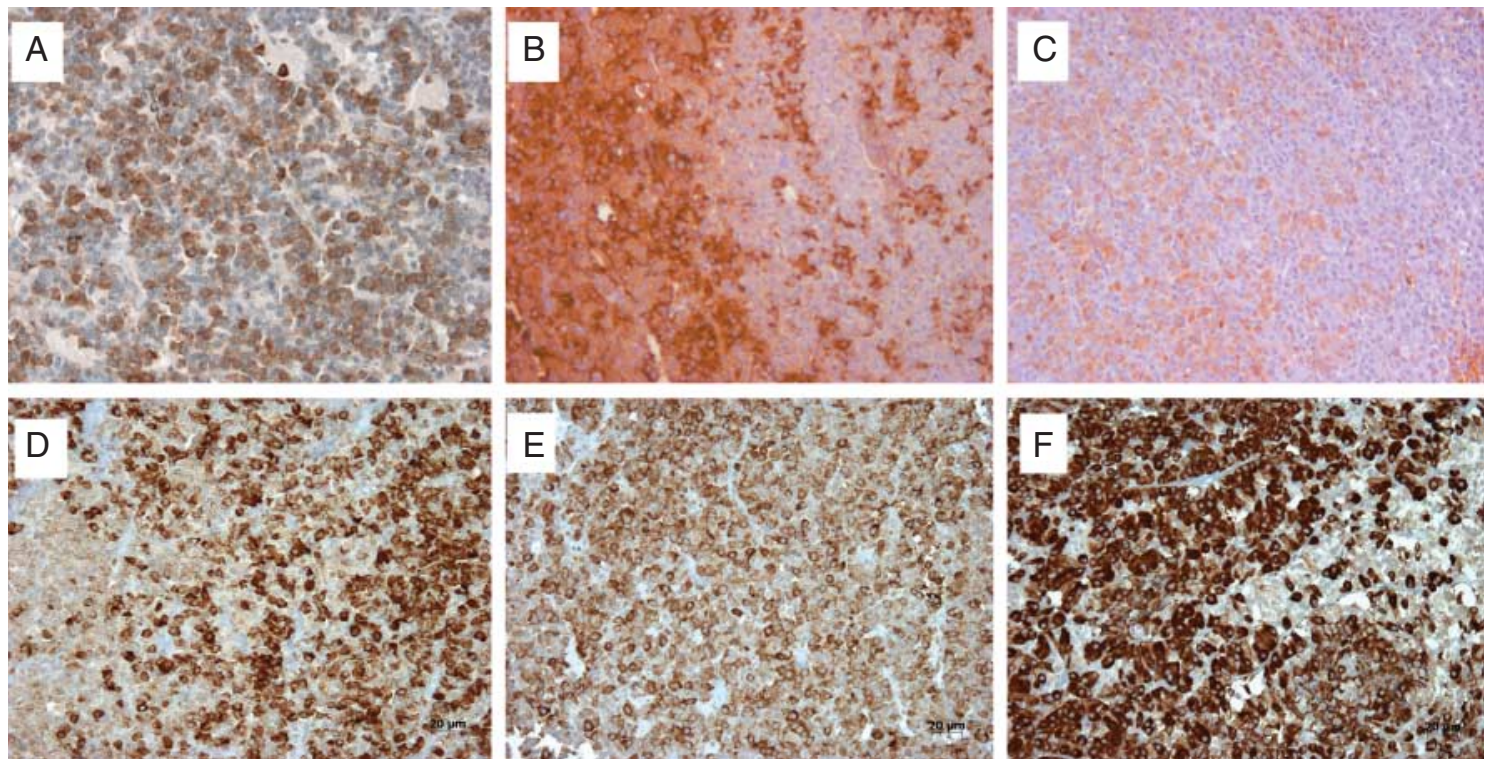

\section{Figure 5}

Immunohistochemistry of pituitary adenomas from X-LAG syndrome cases. In case S1 (sporadic male), panel A shows strong GHRHR staining (brown) in the pituitary adenoma with a C-terminal GHRHR peptide (20× magnification). The tumor was a mixed GH and PRL adenoma and staining of consecutive slices demonstrated largely different cell populations that stained for GH (brown; panel B) and PRL (brown; C).

weight (+4.4 SDS) at diagnosis. Patients with X-LAG have a spectrum of signs and symptoms apart from the increased growth. Many of these signs echo the clinical features of GH excess observed in adult acromegaly, including acral enlargement and facial coarsening. Among the cohort, the increase in foot size was remarked upon in many cases. In terms of facial changes, some patients appeared to exhibit hypertelorism as part of the overall coarsening of the nose and brow, which would differ from adult acromegaly. Prognathism itself was rare, but, in three cases, patients also developed a widening of the interdental spaces (Fig. 2). Other acromegalic features such as increased perspiration/body odor, sleep apnea, and skin thickening were also reported variably. Unusually, more than a third of patients had abnormally increased appetite, which has not, to our knowledge, been reported in association with gigantism previously. This and the presence of hyperinsulinemia and acanthosis nigricans indicate that there are metabolic effects that either stem from or accompany the process of somatic overgrowth in affected children. The appearance of acromegaly signs and symptoms in a young child should raise a high suspicion of an underlying Xq26.3 microduplication.

Treatment of pediatric patients with PAs is complex, particularly in those - similar to the X-LAG syndrome
SSTR immunohistochemistry was also performed on tumors from patients with the Xq26.3 microduplication. AIP staining (brown) shown for three pituitary tumors from X-LAG syndrome cases (D, E, and F). In all six cases the tested AIP staining was preserved at moderate to high levels and was predominantly cytoplasmic $(20 \times$ magnification).

cohort - where the tumor is large and the children are very young (Jane 2008). A desire for disease control must be acutely balanced against attempts to maintain normal function in other anterior pituitary axes while avoiding DI. The current study highlights for the first time, the challenges that have been encountered in treating patients with X-LAG syndrome. SSAs are the mainstay of medical treatment of GH excess, but in the setting of X-LAG syndrome their efficacy was poor. No patient achieved primary or secondary control of their disease or GH/IGF1 with SSA, even when using adult doses in young children. We report new data on SSTR levels in PAs from X-LAG patients, which indicate that the poor SSA responses to octreotide and lanreotide are not due to low SSTR2 expression, which was preserved in all cases. Indeed, in two cases, SSTR2 levels were very high despite a lack of control of GH or IGF1 with chronic SSA use at adult-type doses. The genomic abnormality encountered in X-LAG with tumoral GPR101 overexpression could, in turn, hypothetically promote growth by concomitantly down-regulating important signaling elements (e.g., ZAC1) linked to SSA effects (Theodoropoulou et al. 2009). A similar but less dramatic scenario has also been noted to occur with respect to the significantly decreased

Published by Bioscientifica Ltd 


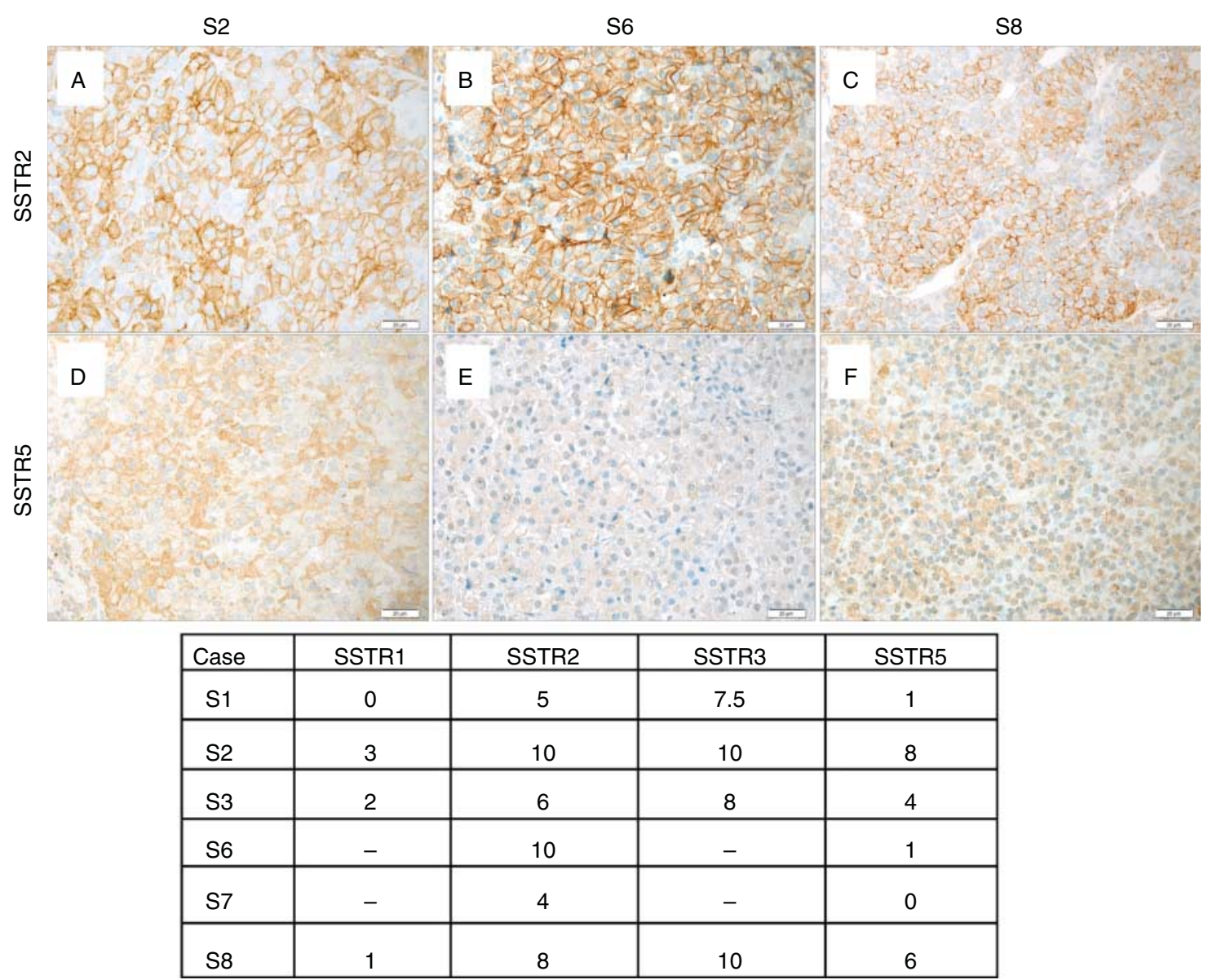

Figure 6

SSTR immunohistochemistry was performed on tumors from patients with the Xq26.3 microduplication and results are shown in the tabulation (lower panel). Expression of SSTR2 in representative tumor samples of three X-LAG patients is shown in panels A, B, and C and that of SSTR5 in

responses to SSA in patients with AIP mutation-associated acromegaly (Daly et al. 2010, Chahal et al. 2012). However, staining for AIP, which can be reduced in tumors of acromegaly patients with poor SSA responses (Kasuki et al. 2012, Jaffrain-Rea et al. 2013), was preserved in X-LAG patients. Other SSTRs were also preserved to a variable extent, including SSTR5 and SSTR3, which would indicate that treatment of patients with X-LAG by targeting these receptors with a multi-receptor SSA like pasireotide might be of clinical interest (Cuevas-Ramos \& Fleseriu 2014, Eigler et al. 2014). A medical option to achieve control of IGF1 and physical overgrowth involved the use of pegvisomant, either alone or in combination with SSA/DA in a postoperative setting. This option, while useful, needs to be balanced against the lack of safety data for pegvisomant in the pediatric setting, although use in panels D, E, and F. Immunoreactive scores for SSTR2 for all three samples illustrated were high, whereas SSTR5 scores varied from negative to high (S2) level. Original magnification: $\times 400$. Scale bar: $20 \mu \mathrm{m}$.

pediatric cases has been reported and, in the current cohort, no evidence of tumor expansion during pegvisomant monotherapy was noted (Rix et al. 2005, Mussig et al. 2007, Goldenberg et al. 2008, Daniel et al. 2013). DA alone was not sufficient to achieve control of hormonal hypersecretion in these cases. Neurosurgery was performed or planned in all cases and represents an effective option but was frequently associated with significant pituitary dysfunction (including GH deficiency). It should be noted that in cases where global pituitary hyperplasia is found, significant hypopituitarism is probably unavoidable when pursuing successful surgical resection of pathological tissue. On the other hand, a very small residual tumor was capable of maintaining levels of GH/IGF1 above normal for many years, thereby necessitating chronic medical therapy. These residual tumor

Published by Bioscientifica Ltd 
tissues did not regrow significantly, which might be due to the low proliferative index observed in most cases; radiotherapy could also have played a role in preventing tumor regrowth but the current cohort is probably still too limited to draw conclusions about the role of radiotherapy in X-LAG syndrome. Achievement of control of pediatric overgrowth in the narrow window before this overgrowth became adult gigantism required recourse to radical surgery or multimodal combination therapy in the current cohort.

A unifying feature of the X-LAG syndrome is the strikingly early age at onset, given that phenotypically the affected children are born normal and in sporadic cases come from normal-sized families. The generally normal prenatal growth in these cases is probably due to the fact that in utero growth is mediated mainly by IGF2. The early onset of post-natal overgrowth may be in keeping with the ontogeny of the maturing hypothalamus and pituitary during late fetal and early neonatal life. Activity of the fetal somatotrope axis is high at full term and GH secretion reaches one of the lifetime peaks on day 1 of postnatal life (Coutant \& Bouhours-Nouet 2012, Veldhuis et al. 2012). Somatotrope axis regulation in early neonatal life in animals appears to promote the maintenance of $\mathrm{GH}$ secretory responses to GHRH (less desensitization), while this effect is accompanied by high levels of GHRH in infant animals and the induction by GHRH of its own receptor, GHRHR, only during early life which later wanes and disappears (Cuttler et al. 1993, 1995, Collins et al.
1996, Torronteras et al. 1996, 1997, 2012). These factors could represent a window during which increased GHRH secretion in a young patient could lead to upregulation of pituitary GHRHR and the subsequent cellular and hormonal over-activity.

The molecular etiology of the pituitary pathology remains a matter of debate. As we had demonstrated previously, of the four candidate coding genes contained within the common duplicated region, only GPR101 was upregulated at the level of pituitary tumor tissue, implicating a role for this GPCR in the pituitary itself (Trivellin et al. 2014). The finding that the GH/PRL hypersecretion was accompanied by normal or slightly elevated GHRH secretion (in the absence of peripheral sources on imaging scans) indicates that hypothalamic GHRH dysregulation may also play a part in the etiology. Results from previous studies of patients with disease phenotypes that closely resemble X-LAG syndrome also indicate an important role for GHRH (Moran et al. 1990, Zimmerman et al. 1993, Dubuis et al. 1995). Other factors support this hypothesis. The pathology observed has similarities to two entities caused by GHRH hypersecretion. Endocrine malignancies, such as bronchial or pancreatic neuroendocrine tumors (NETs), may rarely secrete GHRH. This scenario leads to unregulated hyperstimulation of pituitary somatotropes and hyperplasia of these cells and concomitant GH/IGF1 excess (Zatelli et al. 2005, Garby et al. 2012). Such NETs occurring as they do in adults lead to a phenotype of

Table 3 Historical cases of extreme gigantism in which growth began in early childhood

\begin{tabular}{|c|c|c|c|c|c|c|c|}
\hline Name & Country & Sex & $\begin{array}{l}\text { Year of } \\
\text { birth }\end{array}$ & $\begin{array}{l}\text { Birth } \\
\text { weight }(\mathrm{kg})\end{array}$ & $\begin{array}{c}\text { Normal } \\
\text { family } \\
\text { history }\end{array}$ & $\begin{array}{l}\text { Age at onset } \\
\text { of abnormal } \\
\text { growth (years) }\end{array}$ & $\begin{array}{c}\text { Final } \\
\text { height }(\mathrm{cm})\end{array}$ \\
\hline Martin Van Buren Bates ${ }^{a}$ & USA & $\mathrm{M}$ & 1837 & Normal & $Y$ & 6 & 222 \\
\hline Anna Haining Swan ${ }^{a}$ & Canada & $\mathrm{F}$ & 1846 & 8.1 & Y & $<4$ & 227 \\
\hline Ella Kate Ewing & USA & $\mathrm{F}$ & 1872 & 3.4 & Y & 7 & 225 \\
\hline Fedor Andreevich Machnow & Russia & $\mathrm{M}$ & 1878 & NA & $\mathrm{Y}$ & 5 & 239 \\
\hline Edouard Beaupréb & Canada & $\mathrm{M}$ & 1881 & 4.1 & Y & 3 & 251 \\
\hline Joh(a)n Aasen ${ }^{b}$ & USA & $\mathrm{M}$ & 1890 & NA & No & $<8$ & 218 \\
\hline Albert Johan Kramer ${ }^{b}$ & The Netherlands & $\mathrm{M}$ & 1897 & 8.5 & $Y$ & $<7$ & 238 \\
\hline Robert Pershing Wadlow ${ }^{b}$ & USA & $\mathrm{M}$ & 1918 & 4.1 & $Y$ & $<3$ & 272 \\
\hline Cecil Boling & USA & $\mathrm{M}$ & 1920 & Normal & Y & $<7$ & 235 \\
\hline Rigardus Rijnhout $^{\mathrm{b}}$ & The Netherlands & $\mathrm{M}$ & 1922 & Normal & Y & $>3$ & 238 \\
\hline Dolores Ann Pullard ${ }^{b}$ & USA & $\mathrm{F}$ & 1946 & Normal & $\mathrm{Y}$ & 4 & 227 \\
\hline Sandra Elaine (Sandy) Allen ${ }^{b}$ & USA & $\mathrm{F}$ & 1955 & 2.95 & Y & 3 & 232 \\
\hline Zeng Jinlian & China & $\mathrm{F}$ & 1965 & Normal & $\mathrm{Y}$ & $<1$ & 249 \\
\hline Yao Defen ${ }^{b}$ & China & $\mathrm{F}$ & 1972 & 2.8 & $Y$ & $<3$ & 234 \\
\hline
\end{tabular}

${ }^{a}$ Swan and Bates were married and had two pregnancies; one female child was stillborn (weighed $8.1 \mathrm{~kg}$ ) and later a son who died in early infancy was $10.8 \mathrm{~kg}$ and $76 \mathrm{~cm}$ in length when born.

${ }^{\mathrm{b}}$ Cases for which pituitary pathology was reliably diagnosed/reported. 
acromegaly and are associated with highly increased GHRH levels in the peripheral blood. However, in cases where such patients have been mistakenly operated on for their pituitary pathology before their peripheral GHRH source was identified, adenomatous changes are rarely encountered (Borson-Chazot et al. 2012). This is in contrast to our infant-onset gigantism cohort in which hyperplasia occurs in a minority of cases and mixed GHand prolactin-secreting adenomas predominate. The second relevant setting is that of GHRH-overexpressing transgenic mouse models (Hammer et al. 1985). While these mice have elevated circulating GHRH levels, their pituitary and growth phenotypes are instructive. Such mice develop a spectrum of mixed GH- and prolactinsecreting PAs, with or without accompanying somatotrope, lactotrope, or mammosomatotrope hyperplasia (Mayo et al. 1988, Brar et al. 1989, Stefaneanu et al. 1989, Asa et al. 1990, 1992). It has been suggested that the process behind tumorigenesis in these GHRH transgenic mice involves an evolution from normal tissue through hyperplasia to adenoma formation (Lloyd et al. 1992, Umemura et al. 1995). Another element implicating GHRH in the etiology of this infant-onset gigantism syndrome is the widespread presence of GHRHR in hyperplastic and adenomatous tissue, as compared with normal pituitary. Such a presence of GHRHR would seem to be a pre-requisite for a GHRH-driven disease, particularly as local pituitary GHRH sources were not found on IHC (Trivellin et al. 2014).

Most X-LAG syndrome patients were females and occurred sporadically in genetically normal families, probably due to new mutations. While transmission was dominant in all three offspring in the two kindreds with $\mathrm{X}$-LAG syndrome, currently only transmission from affected mother to affected son has been observed; the only unaffected offspring was a clinically and genetically normal female. There are no cases so far of disease transmission of affected male to offspring. The preponderance of cases of sporadic females might be due to the potential negative effect of an Xq26.3 microduplication on the viability of hemizygous male embryos.

X-LAG syndrome may explain the etiology of some of the most severe cases of gigantism. As we had described previously, the medical literature from 1970 (when GH hypersecretion could be proven by assay) contains reports of cases with similar clinical features to the X-LAG syndrome cohort (Trivellin et al. 2014), to which others can be added (Spence et al. 1972, AvRuskin et al. 1973). Other earlier cases of infant-onset pituitary gigantism were well described medically (Todd 1958, de Majo \& Oñativia 1960, Hurxthal 1961) and again mirror X-LAG syndrome closely. Parsing these historical reports and some accompanying scientific observations reveals information indicating that many of the tallest patients in history had an early childhood-onset gigantism phenotype that is highly reminiscent of X-LAG syndrome. As shown in Table 3, these cases occurred against a background of a normal family history and, in some, a pituitary pathology was demonstrable. At present, the clinical syndrome that most closely fits the etiology of these cases is X-LAG syndrome. These cases of extreme gigantism in adults underline the need for effective therapy to arrest tumor-induced growth during childhood.

$\mathrm{X}$-LAG syndrome is a new, rare disorder of pituitary gigantism associated with a phenotype of overgrowth due to mixed GH- and PRL-secreting PAs/hyperplasia that usually begins during the first 2 years of life. Early recognition of these cases may be helped by better clinical awareness of the characteristic acromegalic symptomatology; diagnosis of the underlying Xq26.3 microduplication is readily achievable using clinical aCGH. Management of X-LAG syndrome is complicated by the high baseline levels of GH hypersecretion and therapeutic control of abnormal growth requires radical surgical resection or multimodal therapy including pegvisomant. SSA responses are poor despite the presence of moderate to high levels of SSTR2 staining. The underlying pathophysiology of X-LAG remains to be explained fully, particularly the role of GPR101 in regulating tumor growth by modulating hypothalamic or pituitary signals.

\section{Supplementary data}

This is linked to the online version of the paper at http://dx.doi.org/10.1530/ ERC-15-0038

\section{Declaration of interest}

The authors declare that there is no conflict of interest that could be perceived as prejudicing the impartiality of the research reported.

\section{Funding}

This study was supported by the US Department of Health and Human Services-National Institutes of Health-National Institute of Child Health and Human Development (Z01-HD008920), US Department of Health and Human Services-National Institutes of Health-National Human Genome Research Institute (U54HG006542), Fonds D'Investissement de Recherche Scientifique, CHU de Liège, Jabbs Foundation, and National Institute of Neurological Disorders and Stroke (NINDS) (R01 NS058529).

Published by Bioscientifica Ltd. 


\section{References}

Asa SL, Kovacs K, Stefaneanu L, Horvath E, Billestrup N, GonzalezManchon C \& Vale W 1990 Pituitary mammosomatotroph adenomas develop in old mice transgenic for growth hormone-releasing hormone. Proceedings of the Society for Experimental Biology and Medicine. Society for Experimental Biology and Medicine 193 232-235. (doi:10.3181/ 00379727-193-3-RC1)

Asa SL, Kovacs K, Stefaneanu L, Horvath E, Billestrup N, GonzalezManchon C \& Vale W 1992 Pituitary adenomas in mice transgenic for growth hormone-releasing hormone. Endocrinology 131 2083-2089. (doi:10.1210/endo.131.5.1425411)

AvRuskin TW, Sau K, Tang S \& Juan C 1973 Childhood acromegaly: successful therapy with conventional radiation and effects of chlorpromazine on growth hormone and prolactin secretion. Journal of Clinical Endocrinology and Metabolism 37 380-388. (doi:10.1210/jcem37-3-380)

Beckers A, Aaltonen LA, Daly AF \& Karhu A 2013 Familial isolated pituitary adenomas (FIPA) and the pituitary adenoma predisposition due to mutations in the aryl hydrocarbon receptor interacting protein (AIP) gene. Endocrine Reviews 34 239-277. (doi:10.1210/er.2012-1013)

Borson-Chazot F, Garby L, Raverot G, Claustrat F, Raverot V, Sassolas G \& GTE Group 2012 Acromegaly induced by ectopic secretion of GHRH: a review 30 years after GHRH discovery. Annales d'Endocrinologie $\mathbf{7 3}$ 497-502. (doi:10.1016/j.ando.2012.09.004)

Brar AK, Brinster RL \& Frohman LA 1989 Immunohistochemical analysis of human growth hormone-releasing hormone gene expression in transgenic mice. Endocrinology 125 801-809. (doi:10.1210/endo125-2-801)

Chahal HS, Trivellin G, Leontiou CA, Alband N, Fowkes RC, Tahir A, Igreja SC, Chapple JP, Jordan S, Lupp A et al. 2012 Somatostatin analogs modulate AIP in somatotroph adenomas: the role of the ZAC1 pathway. Journal of Clinical Endocrinology and Metabolism 97 1-10. (doi:10.1210/ jc.2012-1111)

Collins BJ, Szabo M \& Cuttler L 1996 Differential desensitization response of the neonatal and adult rat somatotroph to growth hormone-releasing hormone and phorbol ester. Molecular and Cellular Endocrinology 117 75-81. (doi:10.1016/0303-7207(95)03731-4)

Coutant R \& Bouhours-Nouet N 2012 Endocrine control and regulation of growth hormone: an overview. In Handbook of Growth and Growth Monitoring in Health and Disease, pp 73-92. Ed VR Preedy. New York, NY: Spinger Science + Business Media, LLC.

Cuevas-Ramos D \& Fleseriu M 2014 Somatostatin receptor ligands and resistance to treatment in pituitary adenomas. Journal of Molecular Endocrinology 52 R223-R240. (doi:10.1530/JME-14-0011)

Cuttler L, Collins BJ, Marone PA \& Szabo M 1993 The effect of isobutylmethylxanthine, forskolin, and cholera toxin on growth hormone release from pituitary cell cultures of perinatal and mature rats. Endocrine Research 19 33-46. (doi:10.3109/ 07435809309035406)

Cuttler L, Collins BJ \& Szabo M 1995 Ontogeny of the GH response to phorbol ester and phospholipase C in rat pituitary cells. Journal of Endocrinology 145 307-314. (doi:10.1677/joe.0.1450307)

Daly AF, Tichomirowa MA, Petrossians P, Heliövaara E, Jaffrain-Rea M-L, Barlier A, Naves LA, Ebeling T, Karhu A, Raappana A et al. 2010 Clinical characteristics and therapeutic responses in patients with germ-line AIP mutations and pituitary adenomas: an international collaborative study. Journal of Clinical Endocrinology and Metabolism 95 E373-E383. (doi:10.1210/jc.2009-2556)

Daniel A, d'Emden M \& Duncan E 2013 Pituitary gigantism treated successfully with the growth hormone receptor antagonist, pegvisomant. Internal Medicine Journal 43 345-347. (doi:10.1111/imj.12077)

Davies JH \& Cheetham T 2014 Investigation and management of tall stature. Archives of Disease in Childhood 99 772-777. (doi:10.1136/ archdischild-2013-304830)
Dubuis JM, Deal CL, Drews RT, Goodyer CG, Lagace G, Asa SL, Van Vliet G \& Collu R 1995 Mammosomatotroph adenoma causing gigantism in an 8-year old boy: a possible pathogenetic mechanism. Clinical Endocrinology 42 539-549. (doi:10.1111/j.1365-2265.1995.tb02675.x)

Eigler T, Ben-Shlomo A, Zhou C, Khalafi R, Ren SG \& Melmed S 2014 Constitutive somatostatin receptor subtype-3 signaling suppresses growth hormone synthesis. Molecular Endocrinology 28 554-564. (doi:10.1210/me.2013-1327)

Eugster EA \& Pescovitz OH 1999 Gigantism. Journal of Clinical Endocrinology and Metabolism 84 4379-4384. (doi:10.1210/jcem.84.12.6222)

Garby L, Caron P, Claustrat F, Chanson P, Tabarin A, Rohmer V, Arnault G, Bonnet F, Chabre O, Christin-Maitre S et al. 2012 Clinical characteristics and outcome of acromegaly induced by ectopic secretion of growth hormone-releasing hormone (GHRH): a French nationwide series of 21 cases. Journal of Clinical Endocrinology and Metabolism 97 2093-2104. (doi:10.1210/jc.2011-2930)

Goldenberg N, Racine MS, Thomas P, Degnan B, Chandler W \& Barkan A 2008 Treatment of pituitary gigantism with the growth hormone receptor antagonist pegvisomant. Journal of Clinical Endocrinology and Metabolism 93 2953-2956. (doi:10.1210/jc.2007-2283)

Hammer RE, Brinster RL, Rosenfeld MG, Evans RM \& Mayo KE 1985 Expression of human growth hormone-releasing factor in transgenic mice results in increased somatic growth. Nature 315 413-416. (doi:10.1038/315413a0)

Hastings PJ, Ira G \& Lupski JR 2009 A microhomology-mediated breakinduced replication model for the origin of human copy number variation. PLoS Genetics 5 e1000327. (doi:10.1371/journal.pgen. 1000327)

de Herder WW 2015 The history of acromegaly. Neuroendocrinology (In Press). (doi:10.1159/000371808)

Hurxthal LM 1961 Pituitary gigantism in a child five years of age: effect of $\mathrm{x}$-radiation, estrogen therapy and self-imposed starvation diet during an eleven-year period. Journal of Clinical Endocrinology and Metabolism 21 343-353. (doi:10.1210/jcem-21-3-343)

Jaffrain-Rea ML, Angelini M, Gargano D, Tichomirowa MA, Daly AF, Vanbellinghen JF, D'Innocenzo E, Barlier A, Giangaspero F, Esposito V et al. 2009 Expression of aryl hydrocarbon receptor (AHR) and AHR-interacting protein in pituitary adenomas: pathological and clinical implications. Endocrine-Related Cancer 16 1029-1043. (doi:10.1677/ERC-09-0094)

Jaffrain-Rea ML, Rotondi S, Turchi A, Occhi G, Barlier A, Peverelli E, Rostomyan L, Defilles C, Angelini M, Oliva MA et al. 2013 Somatostatin analogues increase AIP expression in somatotropinomas, irrespective of Gsp mutations. Endocrine-Related Cancer 20 753-766. (doi:10.1530/ERC12-0322)

Jane JA Jr 2008 Management of pediatric sellar tumors. Pediatric Endocrinology Reviews 5 (Suppl 2) 720-726.

Kasuki L, Vieira Neto L, Wildemberg LE, Colli LM, De Castro M, Takiya CM \& Gadelha MR 2012 AIP expression in sporadic somatotropinomas is a predictor of the response to octreotide LAR therapy independent of SSTR2 expression. Endocrine-Related Cancer 19 L25-L29. (doi:10.1530/ ERC-12-0020)

Lee JA, Carvalho CM \& Lupski JR 2007 A DNA replication mechanism for generating nonrecurrent rearrangements associated with genomic disorders. Cell 131 1235-1247. (doi:10.1016/j.cell.2007.11.037)

Lee M, Marinoni I, Irmler M, Psaras T, Honegger JB, Beschorner R, Anastasov N, Beckers J, Theodoropoulou M, Roncaroli F et al. 2013 Transcriptome analysis of MENX-associated rat pituitary adenomas identifies novel molecular mechanisms involved in the pathogenesis of human pituitary gonadotroph adenomas. Acta Neuropathologica 126 137-150. (doi:10.1007/s00401-013-1132-7)

Lee M, Lupp A, Mendoza N, Martin NM, Beschorner R, Honegger J, Schlegel J, Shively T, Pulz E, Schulz S et al. 2014 SSTR3 is a putative target for the medical treatment of gonadotroph adenomas of the pituitary. Endocrine-Related Cancer 22 111-119. (doi:10.1530/ ERC-14-0472) 
Lloyd RV, Jin L, Chang A, Kulig E, Camper SA, Ross BD, Downs TR \& Frohman LA 1992 Morphologic effects of hGRH gene expression on the pituitary, liver, and pancreas of MT-hGRH transgenic mice. An in situ hybridization analysis. American Journal of Pathology 141 895-906.

Magri F, Villa C, Locatelli D, Scagnelli P, Lagonigro MS, Morbini P, Castellano M, Gabellieri E, Rotondi M, Solcia E et al. 2010 Prevalence of double pituitary adenomas in a surgical series: clinical, histological and genetic features. Journal of Endocrinological Investigation 33 325-331. (doi:10.1007/BF03346594)

de Majo SF \& Oñativia A 1960 Acromegaly and gigantism in a boy: comparison with 3 overgrown nonacromegalic children. Journal of Pediatrics 57 382-390. (doi:10.1016/S0022-3476(60)80246-6)

Mayo KE, Hammer RE, Swanson LW, Brinster RL, Rosenfeld MG \& Evans RM 1988 Dramatic pituitary hyperplasia in transgenic mice expressing a human growth hormone-releasing factor gene. Molecular Endocrinology 2 606-612. (doi:10.1210/mend-2-7-606)

Moran A, Asa S, Kovacs K, Horvath E, Singer W, Sagman U, Reubi J, Wilson C, Larson R \& Pescovits O 1990 Gigantism due to pituitary mammosomatotroph hyperplasia. New England Journal of Medicine 323 322-327. (doi:10.1056/NEJM199008023230507)

Mussig K, Gallwitz B, Honegger J, Strasburger CJ, Bidlingmaier M, Machicao F, Bornemann A, Ranke MB, Haring HU \& Petersenn S 2007 Pegvisomant treatment in gigantism caused by a growth hormonesecreting giant pituitary adenoma. Experimental and Clinical Endocrinology \& Diabetes 115 198-202. (doi:10.1055/s-2007-956172)

Rix M, Laurberg P, Hoejberg AS \& Brock-Jacobsen B 2005 Pegvisomant therapy in pituitary gigantism: successful treatment in a 12-year-old girl. European Journal of Endocrinology/European Federation of Endocrine Societies 153 195-201. (doi:10.1530/eje.1.01956)

Salenave S, Boyce AM, Collins MT \& Chanson P 2014 Acromegaly and McCune-Albright syndrome. Journal of Clinical Endocrinology and Metabolism 99 1955-1969. (doi:10.1210/jc.2013-3826)

Salpea P \& Stratakis CA 2014 Carney complex and McCune-Albright syndrome: an overview of clinical manifestations and human molecular genetics. Molecular and Cellular Endocrinology 386 85-91. (doi:10.1016/j.mce.2013.08.022)

Spence HJ, Trias EP \& Raiti S 1972 Acromegaly in a 9 and one-half-year-old boy. Pituitary function studies before and after surgery. American Journal of Diseases of Children 123 504-506. (doi:10.1001/archpedi. 1972.02110110132018)

Stefaneanu L, Kovacs K, Horvath E, Asa SL, Losinski NE, Billestrup N, Price J \& Vale W 1989 Adenohypophysial changes in mice transgenic for human growth hormone-releasing factor: a histological, immunocytochemical, and electron microscopic investigation. Endocrinology 125 2710-2718. (doi:10.1210/endo-125-5-2710)

Stratakis CA, Schussheim DH, Freedman SM, Keil MF, Pack SD, Agarwal SK, Skarulis MC, Weil RJ, Lubensky IA, Zhuang Z et al. 2000 Pituitary macroadenoma in a 5-year-old: an early expression of multiple endocrine neoplasia type 1. Journal of Clinical Endocrinology and Metabolism 85 4776-4780. (doi:10.1210/jcem.85.12.7064)

Theodoropoulou M, Tichomirowa MA, Sievers C, Yassouridis A, Arzberger T, Hougrand O, Deprez M, Daly AF, Petrossians P, Pagotto U et al. 2009 Tumor ZAC1 expression is associated with the response to somatostatin analog therapy in patients with acromegaly. International Journal of Cancer 125 2122-2126. (doi:10.1002/ijc.24602)

Todd RM 1958 Acromegaly in a girl of 8 years. Archives of Disease in Childhood 33 49-54. (doi:10.1136/adc.33.167.49)

Torronteras R, Gracia-Navarro F \& Elsaesser F 1996 Different effects of somatostatin on in vitro growth hormone release in two porcine breeds with different growth rates. Journal of Neuroendocrinology 8 891-900. (doi:10.1111/j.1365-2826.1996.tb00817.x)

Torronteras R, Gracia-Navarro F \& Elsaesser F 1997 Control of growth hormone secretion from porcine fetal and neonatal pituitary tissue in vitro by growth hormone-releasing hormone, somatostatin, and insulin-like growth factor. Neuroendocrinology 65 117-128. (doi:10.1159/000127171)

Torronteras R, Canalejo A \& Elsaesser F 2012 Differential ontogenetic patterns of in vitro desensitization to GHRH in fetal and neonatal anterior pituitary. Neuroendocrinology 95 257-266. (doi:10.1159/ 000333779)

Trivellin G, Daly AF, Faucz FR, Yuan B, Rostomyan L, Larco DO, Schernthaner-Reiter MH, Szarek E, Leal LF, Caberg JH et al. 2014 Gigantism and acromegaly due to Xq26 microduplications and GPR101 mutation. New England Journal of Medicine 371 2363-2374. (doi:10.1056/NEJMoa1408028)

Umemura S, Oda K, Utsunomiya H, Sanno N, Itoh J, Katakami H \& Osamura RY 1995 Immunohistochemical characterization of "hyperplasia-adenoma sequence" in the pituitaries of transgenic mice expressing a human growth hormone-releasing factor gene. Tokai Journal of Experimental and Clinical Medicine 20 71-79.

Veldhuis JD, Iranmanesh A, Erickson E, Roelfsema F \& Bowers CY 2012 Lifetime regulation of growth hormone (GH) secretion. In Handbook of Neuroendocrinology, pp 237-255. Eds G Fink, DW Pfaff \& JW Levine. 1st New York, NY: Academic Press.

Villa C, Lagonigro MS, Magri F, Koziak M, Jaffrain-Rea ML, Brauner R, Bouligand J, Junier MP, Di Rocco F, Sainte-Rose C et al. 2011 Hyperplasia-adenoma sequence in pituitary tumorigenesis related to aryl hydrocarbon receptor interacting protein gene mutation. Endocrine-Related Cancer 18 347-356. (doi:10.1530/ERC11-0059)

Zatelli MC, Maffei P, Piccin D, Martini C, Rea F, Rubello D, Margutti A, Culler MD, Sicolo N \& degli Uberti EC 2005 Somatostatin analogs in vitro effects in a growth hormone-releasing hormone-secreting bronchial carcinoid. Journal of Clinical Endocrinology and Metabolism 90 2104-2109. (doi:10.1210/jc.2004-2156)

Zhang F, Khajavi M, Connolly AM, Towne CF, Batish SD \& Lupski JR 2009 The DNA replication FoSTeS/MMBIR mechanism can generate genomic, genic and exonic complex rearrangements in humans. Nature Genetics 41 849-853. (doi:10.1038/ng.399)

Zimmerman D, Young WF Jr, Ebersold MJ, Scheithauer BW, Kovacs K, Horvath E, Whitaker MD, Eberhardt NL, Downs TR \& Frohman LA 1993 Congenital gigantism due to growth hormone-releasing hormone excess and pituitary hyperplasia with adenomatous transformation. Journal of Clinical Endocrinology and Metabolism 76 216-222. (doi:10.1210/jcem.76.1.8421089)

Received in final form 23 February 2015

Accepted 23 February 2015 http://erc.endocrinology-journals.org

DOI: 10.1530/ERC-15-0038
(C) 2015 Society for Endocrinology Printed in Great Britain
Published by Bioscientifica Ltd 